\title{
Prevention of local lipotoxicity: a new renoprotective mechanism of peroxisome proliferator-activated receptor- $\alpha$ activation in hypertension and obesity?
}

\author{
Xueying Zhao \\ Hypertension Research (2009) 32, 821-823; doi:10.1038/hr.2009.128; published online 14 August 2009
}

$\mathrm{T}$ he renal complications of metabolic syndrome are attributed to multiple factors including insulin resistance, dyslipidemia, hypertension, activation of the renin-angiotensin system (RAS), oxidative stress and inflammation. There is growing evidence that excessive free fatty acids (FFAs) accompanied by triglyceride (TG) accumulation in multiple tissues, including pancreas, skeletal muscle, heart and liver, result in both acute and chronic cell dysfunction and injury. ${ }^{1}$ In the kidney, an altered renal lipid metabolism (elevated TG and low levels of high-density lipoprotein cholesterol) may accelerate the progression to end-stage renal disease by enhancing lipotoxicity, oxidative stress and inflammation. ${ }^{2-7}$ For example, experimental studies have shown that a high-fat diet leads to an altered balance between renal lipogenesis and lipolysis, subsequent renal lipid accumulation, macrophage infiltration, increased oxidative stress and renal injury, including glomerulosclerosis, interstitial fibrosis and albuminuria. ${ }^{4,5}$ Furthermore, it has been suggested that FFAs bound to filtered albumin, rather than albumin itself, cause severe tubulointerstitial damage by promoting the transformation of tubule cells to a proinflammatory phenotype. ${ }^{1,8-10}$

In this issue of Hypertension Research, Shin et al. ${ }^{11}$ have advanced our understanding of these relationships among local FAA accumulation, oxidative stress, inflammation and kidney damage in hypertension and obesity. They clearly demonstrated that an increase

$X$ Zhao is at the Department of Physiology, Morehouse School of Medicine, Atlanta, GA, USA

E-mail: xzhao@msm.edu in intrarenal TG and FFA accumulation was associated with an enhancement of renal structural changes (glomerulosclerosis, inflammation and apoptosis) and functional changes (hypertension and sodium retention) in spontaneously hypertensive rats fed with a high-fat diet (SHR-HF). Importantly, they found that the renal changes in SHR-HF animals were correlated with an inability to upregulate the protein expression of peroxisome proliferator-activated receptor- $\alpha$ (PPAR$\alpha$ ) in the kidney. Fenofibrate, a PPAR $\alpha$ ligand, restored the renal PPAR $\alpha$ level, reduced lipid accumulation and attenuated renal inflammation and damage in this animal model of hypertension and obesity. ${ }^{11}$ This study brings new evidence that pharmacological interventions aimed at improving lipid toxicity and inflammation may represent novel avenues to prevent and/or treat kidney diseases associated with metabolic syndrome.

As a member of the nuclear hormone receptor superfamily, $\operatorname{PPAR} \alpha$ regulates the transcription of an array of genes involved in cellular fatty acid utilization pathways including transport, esterification and oxidation. ${ }^{12,13}$ Previous studies have shown that $\operatorname{PPAR} \alpha$ deficiency aggravates the severity of diabetic nephropathy through an increase in extracellular matrix formation and circulating FFA and TG concentration. ${ }^{14}$ PPAR $\alpha$ ligands could improve renal structure and function by decreasing glomerular hypertrophy and the mesangial matrix in animals with type 1 or type 2 diabetes. ${ }^{14-16}$ In the report by Shin et al., ${ }^{11}$ an HF diet caused a renal depletion of PPAR $\alpha$ parallel to an increase in intrarenal FFA and TG accumulation and renal injury in SHR animals. Treatment of SHR-HF rats with fenofibrate restored PPAR $\alpha$ protein, reduced intrarenal FFA and TG and improved kidney structure and function. These findings imply that the renoprotective effects of fenofibrate are, at least in part, due to local PPAR $\alpha$ activation in SHR-HF animals. This concept is also supported by previous reports that PPAR $\alpha$ is highly expressed in the kidney and might be involved in the control of renal fatty acid $\beta$-oxidation. ${ }^{17,18}$ However, the data generated by Shin et al., ${ }^{11}$ cannot distinguish between a direct pharmacological action of fenofibrate on kidney tissues from its substantial systemic effects, as fenofibrate treatment also improved plasma lipid metabolism, lowered body weight and blood pressure and increased insulin sensitivity in SHR-HF rats (Figure 1). Notably, beneficial effects of weight control have been clearly demonstrated by a recent report that systemic and renal alterations in mice on an HF diet were prevented by body weight control with the dietary restriction of feeding on an HF diet. The finding by Shin et al. ${ }^{11}$ showed that fenofibrate treatment increased serum adiponectin, an anti-inflammatory and antidiabetic adipokine, in the SHR-HF group and also supports the fact that the anti-inflammatory effect of fenofibrate in the kidney could be secondary to systemic drug effects, apart from a decreased renal cell production of inflammatory mediators.

To date, the exact mechanisms by which fibrates exert their renoprotective effects in patients with hypertension and metabolic syndrome are not fully understood, although experimental studies have suggested a role of the cytochrome P450 pathway in the beneficial effect of PPAR $\alpha$ activation. ${ }^{19-22}$ Another 


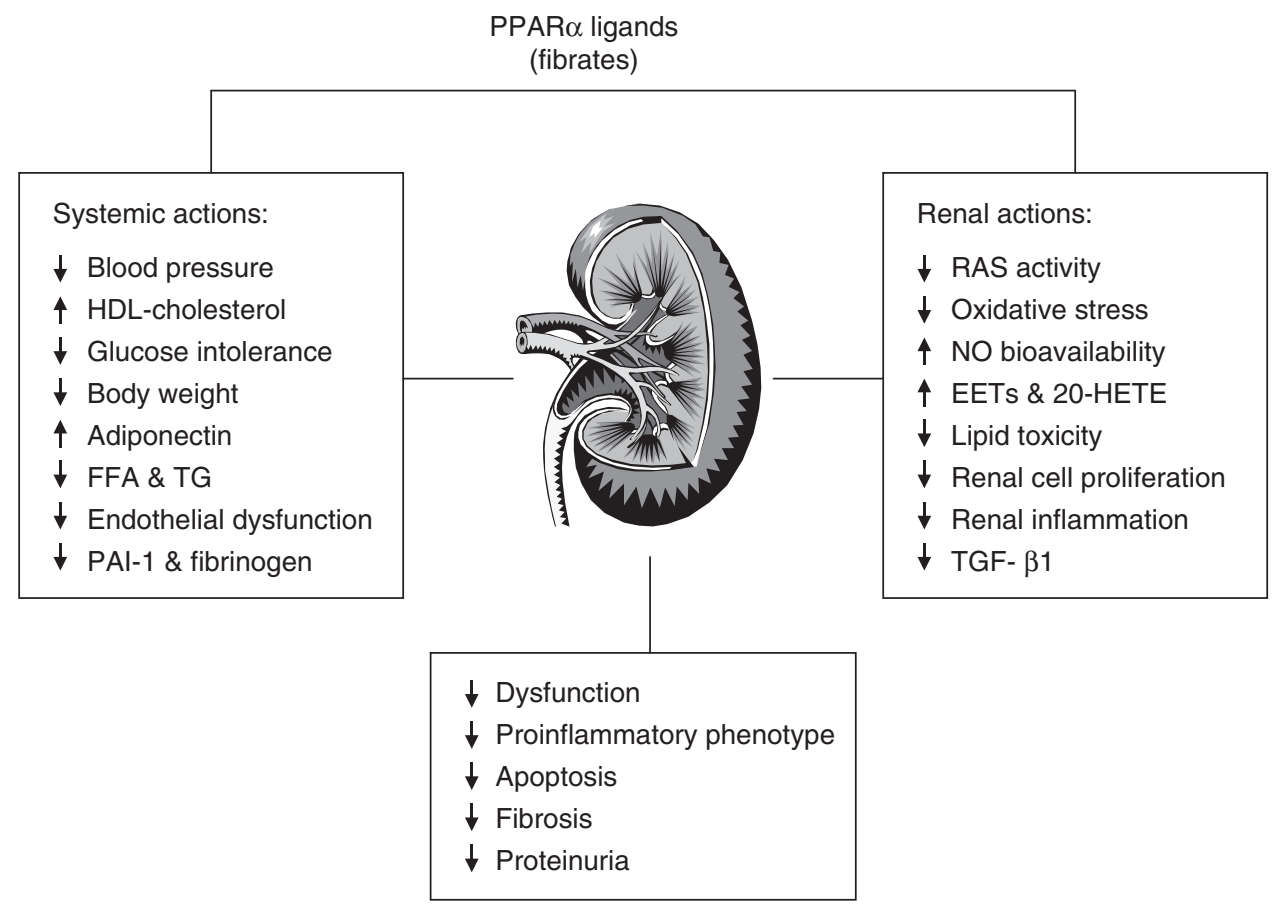

Figure 1 Systemic and renal actions of PPAR $\alpha$ ligands possibly responsible for the improvement of renal structure and function. HDL-cholesterol, highdensity lipoprotein cholesterol; FFA, free fatty acid; TG, triglyceride; PAI-1, plasminogen-activator inhibitor-1; NO, nitric oxide; EETs, epoxyeicosatrienoic acids; 20-HETE, 20-hydroxyeicosatetracnoic acid; TGF- $\beta 1$, transforming growth factor- $\beta 1$.

important finding of the study by Shin et al. ${ }^{11}$ is that the PPAR $\alpha$ content in kidney was negatively correlated with intrarenal angiotensin II concentrations. ${ }^{11}$ They confirmed that renal RAS activity, not systemic, was significantly increased in hypertension and obesity, which was associated with an increase in oxidative stress and a reduction in nitric oxide bioavailability. These findings support the previous published hypothesis that activation of RAS contributes to early glomerular and tubulointerstitial injury, in part through the generation of reactive oxygen species. ${ }^{3,23}$ Interestingly, the increase in renal RAS and oxidative stress was normalized by fenofibrate treatment, suggesting that amelioration of RAS and oxidative stress with fenofibrate could be a mechanism contributing to its renoprotective effects.

It is also worth pointing out that administration of fibrates to patients with mild-tomoderate renal insufficiency has been shown to be associated with a deterioration in renal function with uncertain mechanisms. ${ }^{24}$ Thus, more care should be taken when prescribing fibrates to patients with a preexisting renal dysfunction.

\section{ACKNOWLEDGEMENTS}

This work was supported by the American Heart Association Scientist Development Grant, Satellite Healthcare Norman S Coplon Extramural Research
Grant, NIH/NCRR Grant 5U54RR022814 and NIH/NCRR/RCMI Grant 5G12RR03034-23.

1 Weinberg JM. Lipotoxicity. Kidney Int 2006; 70 : 1560-1566.

2 Hunsicker LG, Adler S, Caggiula A, England BK, Greene T, Kusek JW, Rogers NL, Teschan PE. Predictors of the progression of renal disease in the Modification of Diet in Renal Disease Study. Kidney Int 1997; 51: 1908-1919.

3 Sowers JR. Metabolic risk factors and renal disease. Kidney Int 2007; 71: 719-720.

4 Kume S, Uzu T, Araki S, Sugimoto T, Isshiki K, ChinKanasaki M, Sakaguchi M, Kubota N, Terauchi Y, Kadowaki T, Haneda M, Kashiwagi A, Koya D. Role of altered renal lipid metabolism in the development of renal injury induced by a high-fat diet. J Am Soc Nephrol 2007; 18: 2715-2723.

5 Deji N, Kume S, Araki S, Soumura M, Sugimoto T, Isshiki K, Chin-Kanasaki M, Sakaguchi M, Koya D, Haneda M, Kashiwagi A, Uzu T. Structural and functional changes in the kidneys of high-fat diet-induced obese mice. Am J Physiol Renal Physiol 2009; 296: F118-F126.

6 Jiang T, Wang Z, Proctor G, Moskowitz S, Liebman SE, Rogers T, Lucia MS, Li J, Levi M. Diet-induced obesity in C57BL/6J mice causes increased renal lipid accumulation and glomerulosclerosis via a sterol regulatory element-binding protein-1c-dependent pathway. J Biol Chem 2005; 280: 32317-32325.

7 Proctor G, Jiang T, Iwahashi M, Wang Z, Li J, Levi M. Regulation of renal fatty acid and cholesterol metabolism, inflammation, and fibrosis in Akita and OVE26 mice with type 1 diabetes. Diabetes 2006; 55: 25022509.

8 Kamijo A, Kimura K, Sugaya T, Yamanouchi M, Hase H, Kaneko T, Hirata Y, Goto A, Fujita T, Omata M. Urinary free fatty acids bound to albumin aggravate tubulointerstitial damage. Kidney Int 2002; 62: 1628-1637.

9 Arici M, Chana R, Lewington A, Brown J, Brunskill NJ. Stimulation of proximal tubular cell apoptosis by albumin-bound fatty acids mediated by peroxisome proliferator activated receptor-gamma. J Am Soc Nephrol 2003; 14: 17-27.

10 Thomas ME, Harris KP, Walls J, Furness PN, Brunskill NJ. Fatty acids exacerbate tubulointerstitial injury in protein-overload proteinuria. Am J Physiol Renal Physiol 2002; 283: F640-F647.

11 Shin SJ, Lim JH, Chung S, Youn DY, Chung HW, Kim $\mathrm{HW}$, Lee JH, Chang YS, Park CW. Peroxisome proliferator-activated receptor- $\alpha$ activator fenofibrate prevents high-fat diet-induced renal lipotoxicity in spontaneously hypertensive rats. Hypertens Res 2009; 32: 835-845.

12 Desvergne B, Wahli W. Peroxisome proliferator-activated receptors: nuclear control of metabolism. Endocr Rev 1999; 20: 649-688.

13 Barger PM, Kelly DP. PPAR signaling in the control of cardiac energy metabolism. Trends Cardiovasc Med 2000; 10: 238-245.

14 Park CW, Kim HW, Ko SH, Chung HW, Lim SW, Yang CW, Chang YS, Sugawara A, Guan Y, Breyer MD. Accelerated diabetic nephropathy in mice lacking the peroxisome proliferator-activated receptor alpha. Diabetes 2006; 55: 885-893.

15 Zhao X, Li LY. PPAR-alpha agonist fenofibrate induces renal CYP enzymes and reduces blood pressure and glomerular hypertrophy in Zucker diabetic fatty rats. Am J Nephrol 2008; 28: 598-606.

16 Park CW, Zhang Y, Zhang X, Wu J, Chen L, Cha DR, Su D, Hwang MT, Fan X, Davis L, Striker G, Zheng F, Breyer M, Guan Y. PPARalpha agonist fenofibrate improves diabetic nephropathy in db/db mice. Kidney Int 2006; 69: 1511-1517.

17 Djouadi F, Bastin J. PPARalpha gene expression in the developing rat kidney: role of glucocorticoids. J Am Soc Nephrol 2001; 12: 1197-1203.

18 Ouali F, Djouadi F, Merlet-Benichou C, Bastin J. Dietary lipids regulate beta-oxidation enzyme gene expression in the developing rat kidney. Am J Physiol 1998; 275: F777-F784.

19 Roman RJ, Ma YH, Frohlich B, Markham B. Clofibrate prevents the development of hypertension in Dahl saltsensitive rats. Hypertension 1993; 21: 985-988. 
20 Shatara RK, Quest DW, Wilson TW. Fenofibrate lowers blood pressure in two genetic models of hypertension. Can J Physiol Pharmacol 2000; 78: 367-371.

21 Wang $\mathrm{MH}$, Smith A, Zhou Y, Chang HH, Lin S, Zhao X, Imig JD, Dorrance AM. Downregulation of renal CYP-derived eicosanoid synthesis in rats with diet-induced hypertension. Hypertension 2003; 42 : 594-599.
22 Zhao X, Quigley JE, Yuan J, Wang MH, Zhou Y, Imig JD. PPAR-alpha activator fenofibrate increases renal CYP-derived eicosanoid synthesis and improves endothelial dilator function in obese Zucker rats. $A m$ J Physiol Heart Circ Physiol 2006; 290: H2187H2195.

23 Whaley-Connell AT, Chowdhury NA, Hayden MR, Stump CS, Habibi J, Wiedmeyer CE, Gallagher PE,
Tallant EA, Cooper SA, Link CD, Ferrario C, Sowers JR. Oxidative stress and glomerular filtration barrier injury: role of the renin-angiotensin system in the Ren2 transgenic rat. Am J Physiol Renal Physiol 2006; 291 : F1308-F1314.

24 Lipscombe J, Lewis GF, Cattran D, Bargman JM. Deterioration in renal function associated with fibrate therapy. Clin Nephrol 2001; 55: 39-44. 